\title{
Specific C-Receptors for Itch in Human Skin
}

\author{
Martin Schmelz, ${ }^{1}$ Roland Schmidt, ${ }^{2}$ Andreas Bickel, ${ }^{1}$ Hermann O. Handwerker, ${ }^{1}$ and H. Erik Torebjörk ${ }^{2}$ \\ ${ }^{1}$ Department of Physiology and Experimental Pathophysiology, University of Erlangen-Nürnberg, D-91054 Erlangen, \\ Germany, and ${ }^{2}$ Department of Clinical Neurophysiology, University of Uppsala, S-75185 Uppsala, Sweden
}

In microneurography experiments 56 unmyelinated nerve fibers were studied in the cutaneous branch of the peroneal nerve of healthy volunteers. Units were identified with the "marking" technique as mechanically and heat-responsive $(\mathrm{CMH} ; n=30)$, heat-responsive $(\mathrm{CH} ; n=13)$, or unresponsive to mechanical and heat stimulation $\left(\mathrm{CM}_{\mathrm{i}} \mathrm{H}_{\mathrm{i}} ; n=13\right)$. None of the units showed spontaneous activity.

These units were tested for responsiveness to iontophoresis of histamine (1 mA, $20 \mathrm{sec}$ ) from a small probe (diameter, 6 $\mathrm{mm}$ ), which induced itch sensations lasting several minutes. Twenty-three units were unresponsive to histamine, and 25 units responded weakly with a few spike discharges after iontophoresis.

Eight units, however, responded with sustained discharges to histamine, and their discharge patterns were matching the time course of the itch sensations. All C-units in this group were mechanically insensitive, and five of them were heat-responsive. They had very low conduction velocities of only $0.5 \mathrm{~m} / \mathrm{sec}$, on average, which is significantly lower than conduction velocities of the "polymodal" $\mathrm{CMH}$ units. This slow conduction velocities attributable to small axon diameters may be one reason why these units have not been encountered in previous studies. Histaminesensitive $\mathrm{C}$-units had very large innervation territories extending up to a diameter of $85 \mathrm{~mm}$ on the lower leg.

We conclude that these $\mathrm{C}$-fibers represent a new class of afferent nerve fibers with particularly thin axons but excessive terminal branching. This type of C-fiber probably represents the afferent units long searched for mediating itch sensations.

Key words: microneurography; human; nociceptors; C-fibers; pruritus; histamine
Although the perception of itch poses major problems in medical praxis, its neuronal substrate in the skin has not yet been identified. This is even more surprising because indirect knowledge has accumulated during the last decades about the initiation of itch by external stimuli. It has been proven that most experimental itch stimuli act via histamine release from mast cells, and that application of different concentrations of histamine into the skin causes different degrees of itching (Handwerker et al., 1987; Simone et al., 1987; Magerl et al., 1990). From these observations nerve fibers sensitive to histamine have been postulated (LaMotte et al., 1988; LaMotte, 1992). These presumed "itch units" are probably unmyelinated, because differential blocking of the myelinated fibers in skin nerves does not abolish histamineinduced itching (Handwerker et al., 1987). Pretreatment of the skin with capsaicin, which temporarily destroys unmyelinated nerve endings in the skin (Simone et al., 1996), also abolishes histamine-induced itching (Handwerker et al., 1987).

These should be sufficient data for finding and characterizing the respective units in human skin nerves by means of microneurography, and indeed there are anecdotal reports on responses of cutaneous C-fibers to itching stimuli (Van Hees and Gybels, 1972, 1981; Torebjörk, 1974). It has also been reported that occasionally itch is induced during microstimulation in skin nerves at points

Received June 6, 1997; revised July 21, 1997; accepted July 30, 1997.

This work was supported by a Max Planck Price grant to H.E.T., Deutsche Forschungsgemeinschaft Grant SFB 353, Swedish Medical Council Project 5206, and a grant to R.S. from the Swedish Foundation for Brain Research.

Correspondence should be addressed to Prof. H. O. Handwerker, Department of Physiology and Experimental Pathophysiology, University of Erlangen-Nürnberg, Universitätsstrasse 17, D-91054 Erlangen, Germany.

Copyright (C) 1997 Society for Neuroscience $0270-6474 / 97 / 178003-06 \$ 05.00 / 0$ from which C-fibers were recorded (Torebjörk and Ochoa, 1981). However, the most common type of C-fibers, mechanical and heat nociceptors (CMH or "polymodal nociceptors"), which have been extensively characterized in animal (Bessou and Perl, 1969; Beck et al., 1974; LaMotte and Campbell, 1978; Meyer and Campbell, 1981; Lynn and Carpenter, 1982; Fleischer et al., 1983) and human (Torebjörk, 1974; Gybels et al., 1979; Hallin et al., 1982) skin, are either insensitive to histamine or very weakly activated (Tuckett and Wei, 1987; Handwerker et al., 1991). By no means does the population response of $\mathrm{CMH}$ units match the prolonged itching sensations induced by well defined histamine stimulation, e.g., by intracutaneous injection (Simone et al., 1987) or iontophoretic application from a small probe (Handwerker et al., 1987; Magerl et al., 1990). Hence, CMH units are probably not mediating itch sensations.

Recently we were able to demonstrate new types of C-fibers in human skin by using a microneurography technique, which does not rely on mechanical excitation of nerve endings and allows characterization even of small units having spikes of poor signalto-noise ratio (Schmidt et al., 1995; Torebjörk et al., 1996). C-units are detected by electrical search stimuli, and their activation by histamine, heat, mechanical, or other types of stimulation is documented by transient slowing of impulse conduction velocity (cv) after the response (Schmelz et al., 1995).

This "marking" technique has been used for studying the responsiveness of afferent $\mathrm{C}$-fibers in human skin to controlled histamine application and for comparing these responses with the magnitude and time course of itching. In this paper we present evidence that the putative receptors for itching are $\mathrm{C}$-fibers with exceptionally low conduction velocities and an insensitivity to mechanical stimuli. 


\section{MATERIALS AND METHODS}

Recordings were obtained from 53 subjects (38 male, 13 female; age, 22-32 years) in the microneurography laboratories at Uppsala and Erlangen. In an additional psychophysical study 21 male subjects (age, 21-31 years) rated the sensations produced by histamine stimuli in the absence of nerve recordings.

None of the subjects showed signs of neurological or dermatological disease. The subjects were financially compensated for the time spent in the experiment. They were instructed that they could withdraw from the experiment at any time, and this would not affect the financial compensation. All subjects gave their informed consent, and the study was approved by the local ethics committees.

Methods of microneurography used in this study have been described in detail elsewhere (Schmelz et al., 1994; Schmidt et al., 1995). Microelectrodes were inserted at the level of the fibular head into the superficial branch of the peroneal nerve. When a stable recording position in a nerve fascicle was obtained, the skin field innervated by this fascicle was identified by stroking the skin and listening to the characteristic sound from multifiber discharges of low-threshold mechanosensitive A-fibers. The ensuing search for single $\mathrm{C}$-units was by electrical stimuli to avoid a bias toward mechanically receptive $\mathrm{C}$-units. To this purpose a steel electrode with a blunt tip of $1 \mathrm{~mm}^{2}$ was gently pressed to various points within the respective skin area, and electrical pulses of $0.2 \mathrm{msec}$ duration were delivered from an insulated constant voltage stimulator (Grass S48 or S8). Electrode gel was used to reduce the impedance. Stimulus strength was adjusted to just below the pain threshold of the subject and/or below the stimulus strength, inducing strong twitches of the underlying muscles $(60-100 \mathrm{~V})$. When $\mathrm{C}$-fiber responses were encountered, a pair of needle electrodes, $0.2 \mathrm{~mm}$ in diameter, were inserted at the respective skin site. If necessary, these needle electrodes were readjusted until stable $\mathrm{C}$-fiber responses were obtained to iterative stimulation ( $0.2 \mathrm{msec}, 10-30 \mathrm{~V}, 4 \mathrm{sec}$ interstimulus interval). It has to be pointed out that part of the units encountered by intracutaneous stimulation had not been excited before by the electrical search stimuli from the surface electrode.

When responses of one or several C-fibers to the intracutaneous stimulation were obtained at stable latencies, the marking technique was used for characterizing the unit(s). This technique is based on the slowing of conduction velocity in a C-fiber when it is activated by an additional stimulus (Torebjörk and Hallin, 1974). Pronounced slowing is characteristic for C-fibers and is probably attributable to prolonged changes of membrane properties after excitation. It has been shown that even a single additional spike induced in a $\mathrm{C}$-fiber by a conditioning stimulus produces an increased delay of the subsequent electrically induced spike by about $1 \mathrm{msec}$ (intracutaneous electrical stimulation at 4 $\mathrm{sec}$ intervals). The amount of the delay is strongly correlated to the number of additional spikes (Schmelz et al., 1995).

For characterizing the type of unit with the marking technique, conditioning mechanical and radiant heat stimuli (see below) were applied to the skin in the surroundings of the needle electrodes. For identifying mechanically and thermally insensitive units, epicutaneous electrical stimuli $(0.2 \mathrm{~ms}, 50-100 \mathrm{~V})$ were delivered from the pointed surface electrode gently pressed to the skin. This surface electrode was also used for assessment of the innervation territory. To this purpose the innervation territory was mapped by systematically applying these conditioning electrical stimuli at $2 \mathrm{~mm}$ distances.

According to their responsiveness to mechanical, heat, and electrical stimuli, C-units were classified as mechanically and heat-responsive $(\mathrm{CMH})$, only heat-responsive $(\mathrm{CH})$, or insensitive to physical stimuli $\left(\mathrm{CM}_{\mathrm{i}} \mathrm{H}_{\mathrm{i}}\right)$ (Schmidt et al., 1995). For testing mechanical excitability, calibrated von Frey bristles (Stoelting Co., Chicago, IL) were used. Units responding to mechanical forces up to 1.2 newtons $(\mathrm{N})$ were regarded mechanosensitive. For thermal stimulation radiant heat was delivered from a halogen bulb, and feedback was controlled from a thermocouple attached to the skin as described previously (Beck et al., 1974). Heating started from a baseline of $32^{\circ} \mathrm{C}$. The temperature was raised at $0.25^{\circ} \mathrm{C} /$ sec. The subjects stopped the stimulus when their tolerance level was reached (usually at $50^{\circ} \mathrm{C}$ ). Cutoff temperature was $52^{\circ} \mathrm{C}$.

$\mathrm{C}$-unit responses were recorded and analyzed on a personal computer via an interface card by dedicated software (Forster and Handwerker, 1990). For semiquantitative evaluation of markings, the number of traces was counted in which the conduction delay of the unit under study was increased. It has been previously shown that this measure is closely correlated to the frequency and duration of unitary spike discharges (M.
Schmelz, R. Schmidt, A. Bickel, H. O. Handwerker, and H. E. Torebjörk, unpublished data).

The technique of iontophoretic application of histamine has been used by our group in several studies (Handwerker et al., 1987; Magerl et al., 1990). $1 \%$ histamine dihydrochloride was dissolved in a gel of $2.5 \%$ methylcellulose in distilled water. This jelly was filled into the $50 \mu \mathrm{l}$ cavity of an acrylic applicator $6 \mathrm{~mm}$ in diameter. Current of $1 \mathrm{~mA}$ was delivered for $20 \mathrm{sec}$ from a silver-silver chloride electrode in this applicator to a large reference electrode applied to the skin distally and outside the territory of the peroneal nerve.

In the microneurography study the subjects verbally rated their ensuing itch sensations for $10 \mathrm{~min}$ after iontophoresis at regular intervals on a 10 point scale ( 0 , "no itch"; 10 , "unbearable itch"). In the psychophysical study the subjects rated their histamine-induced sensations on an electronically controlled visual analog scale (VAS) at $10 \mathrm{sec}$ intervals. The VAS again had the end points no itch and unbearable itch.

The method of histamine iontophoresis has been validated before, and it has been proven that current application without histamine, or reversed current flow from a histamine probe, induced neither the characteristic long-lasting itch sensations nor the typical weal and flare reactions (Magerl et al., 1990).

\section{RESULTS}

Fifty-six C-fibers in the superficial peroneal nerve of 53 healthy subjects were identified with regard to their conduction velocity, size of innervation territory, responsiveness to probing the skin with von Frey bristles, and radiant heat stimulation. Thirty units were identified as $\mathrm{CMH}$ (responding to mechanical and heating stimuli), 13 units as $\mathrm{CH}$ (responding to heating but not to probing even with von Frey filaments of $1.2 \mathrm{~N}$ ), and 13 units as $\mathrm{CM}_{\mathrm{i}} \mathrm{H}_{\mathrm{i}}$ ("silent" nociceptors unresponsive to heating the skin up to $52^{\circ} \mathrm{C}$ and to probing with stiff von Frey filaments of $1.2 \mathrm{~N}$ ). Mechanically insensitive units are over-represented in this sample compared with an unselected population (Torebjörk et al., 1996), because we were preferentially searching for them.

All units were tested by iontophoresis of histamine in the vicinity of the intracutaneous needles from which the terminals were electrically excited (1 mA applied for $20 \mathrm{sec}$; see Materials and Methods), and the ensuing itch sensations were rated by the subjects. An additional psychophysical study was performed on another population of subjects to get more precise itch ratings undisturbed by the microneurography situation (see Materials and Methods). Time courses of itching sensations were roughly identical in both studies and also comparable with those in previous studies using the same method (Handwerker et al., 1987; Magerl et al., 1990). Itching started within $30 \mathrm{sec}$ after iontophoresis, usually after termination of the current. It always increased after termination of the current and reached a maximum during the following 2-3 min. Thereafter itch intensity slowly declined, but in most subjects it was still clearly perceived after 10 min. Figure 1, bottom, shows the average time course of itching in 21 subjects.

All polymodal $\mathrm{CMH}$ units but none of the mechanically insensitive $\mathrm{CH}$ and $\mathrm{CM}_{\mathrm{i}} \mathrm{H}_{\mathrm{i}}$ units were activated by the current delivered for iontophoresis, indicating a lower electrical activation threshold of CMHs (also see Fig. 2). A histamine response was only assumed when activation was observed during the first $2 \mathrm{~min}$ after termination of the current when the itching was most intense. Of the 56 units studied, 23 were not excited by histamine (10 $\mathrm{CMH}, 6 \mathrm{CH}$, and $7 \mathrm{CM}_{\mathrm{i}} \mathrm{H}_{\mathrm{i}}$ ). Twenty $\mathrm{CMH}$ units and 5 mechanically insensitive units $\left(\mathrm{CH}\right.$ and $\left.\mathrm{CM}_{\mathrm{i}} \mathrm{H}_{\mathrm{i}}\right)$ were only weakly activated, and their discharges did not match the time course of the itch sensations of the subjects.

The remaining eight units, five $\mathrm{CH}$ and three $\mathrm{CM}_{\mathrm{i}} \mathrm{H}_{\mathrm{i}}$, however, showed long-lasting responses to histamine. The five $\mathrm{CH}$ units had thermal thresholds of $41-46^{\circ} \mathrm{C}$. Four of them were also tested 

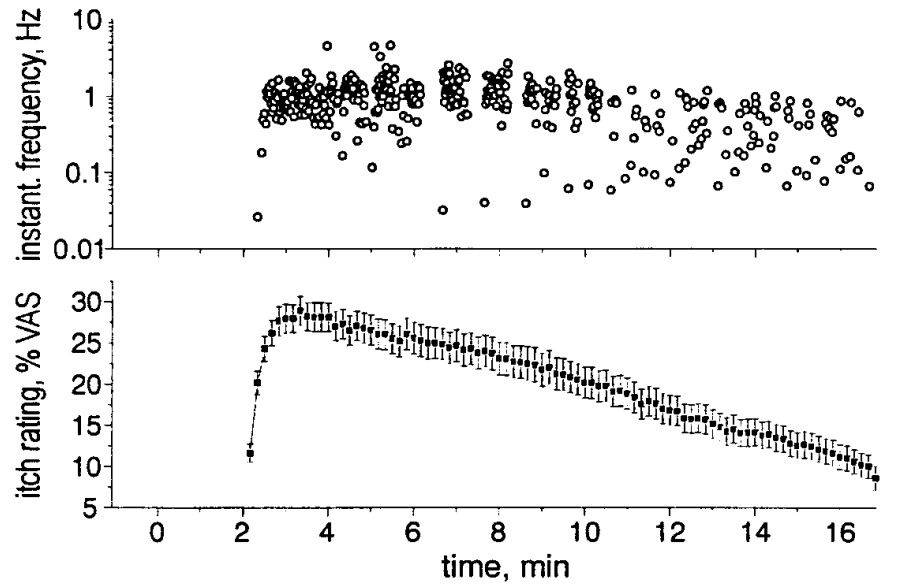

Figure 1. Top, Instantaneous discharge frequency of a mechanically and heat-insensitive $\mathrm{C}$-fiber $\left(\mathrm{CM}_{\mathrm{i}} \mathrm{H}_{\mathrm{i}}\right)$ in the superficial peroneal nerve after histamine iontophoresis ( gray bar). The unit was not spontaneously active before histamine application but continued to fire for a few minutes after termination of the plot. Bottom, Average itch magnitude ratings of a group of 21 healthy volunteers after an identical histamine stimulus. Ratings were at $10 \mathrm{sec}$ intervals on a VAS with the end points no itch and unbearable itch. Error bars indicate SE.

by intracutaneous injection of capsaicin ( $20 \mu \mathrm{l}$ of a $0.1 \%$ solution $)$ and were found to be responsive to this agent.

In one recording of a $\mathrm{CM}_{\mathrm{i}} \mathrm{H}_{\mathrm{i}}$ unit the signal-to-noise ratio was so good that the unit could be analyzed without taking recourse to the marking technique. Figure 1, top, shows the discharge pattern of this unit after histamine iontophoresis compared with the average itch sensations shown in Figure 1, bottom. During the first 4 min after histamine iontophoresis the unit fired at fairly regular intervals of $\sim 1 \mathrm{sec}$. Interestingly, during the following minute interspike intervals did not become much longer, but silent periods interrupted activation periods occurring approximately once per minute.

Figure 2 compares responses of different units with the marking technique (Torebjörk, 1974; Schmidt et al., 1995). In the left panel the histamine response of another $\mathrm{CM}_{\mathrm{i}} \mathrm{H}_{\mathrm{i}}$ unit is shown. Successive spike responses to regular electrical stimulation of the terminals in the skin applied at $4 \mathrm{sec}$ intervals are represented on subsequent sweeps from top to bottom. Each electrical stimulus initiated a sweep, and the conduction delay of the unit can be seen from the abscissa. Histamine activation of the unit is indicated by an increase in conduction delay after electrical test stimuli and hence by a deviation to the right of the trail formed by the successive spike responses of the unit under study. The magnitude of the deviation is closely correlated with the number of additional action potentials elicited in the period before the conditioned spike was induced, and every trace in which the delay was further increased indicates activation in the preceding $4 \mathrm{sec}$ period (Schmelz et al., 1995). Hence, the jagged contour of the trace reflects the irregular bursting of the respective unit. The mechanically and heat-insensitive unit $\left(\mathrm{CM}_{\mathrm{i}} \mathrm{H}_{\mathrm{i}}\right)$ shown in Figure 2, left panel, was not excited by the iontophoresis current (marked at the upper left corner) but responded thereafter for more then 10 min, strongly during the first $3 \mathrm{~min}$, and then with a decreasing number of activation periods. For comparison the discharges of two CMH units are shown (Fig. 2, right panel), which were simultaneously recorded in another experiment. Both units were excited by the iontophoresis current, indicating a lower threshold

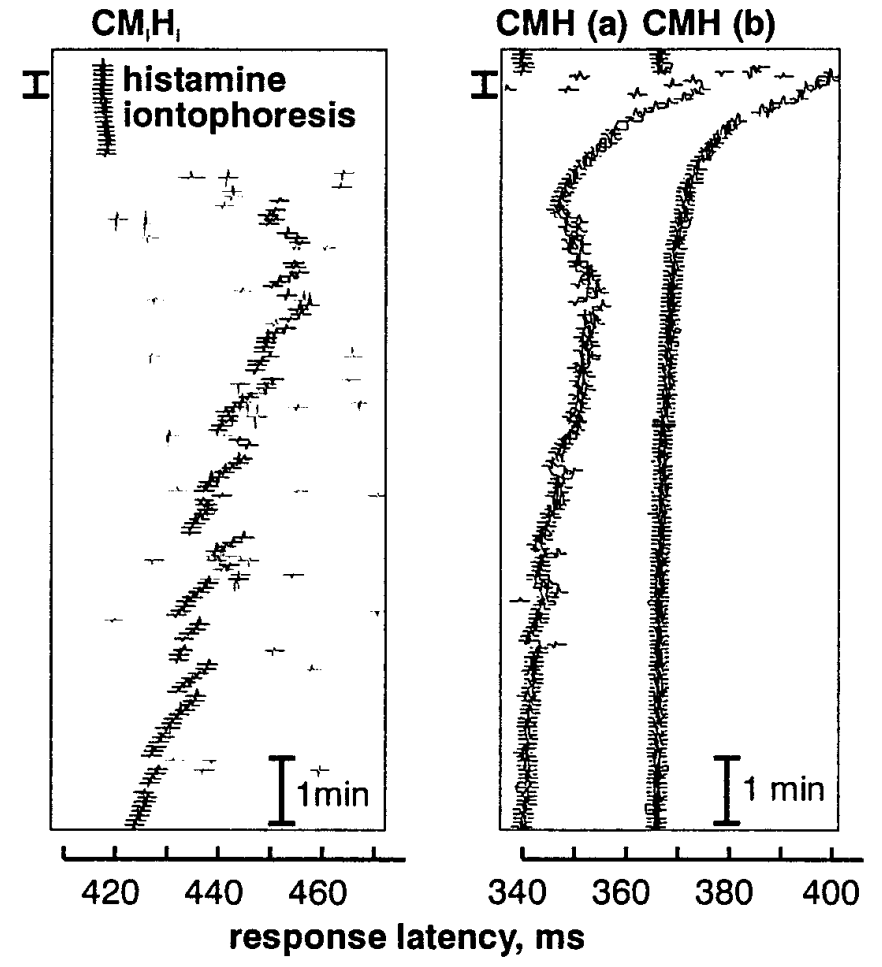

Figure 2. Left panel, Responses of a $\mathrm{CM}_{\mathrm{i}} \mathrm{H}_{\mathrm{i}}$ unit (mechanically and heat-insensitive $\mathrm{C}$-fiber) to histamine iontophoresis are demonstrated with the marking technique. Subsequent spike responses to electrical stimulation at $4 \mathrm{sec}$ intervals are shown from top to bottom. Bold spikes are from the unit under study. Histamine iontophoresis is marked at the upper left corner. Activation of the unit is represented as a deviation of the spike trail to the right. Right panel, The spike trails of two mechanically and heat-responsive $(\mathrm{CMH})$ units are shown, which were simultaneously recorded in another experiment. Both units were excited by the iontophoresis current (marked at left), but only unit $(a)$ shows a weak histamine response.

to activation by electrical stimuli (see above). However, only the unit with the shorter conduction delay (i.e., the faster conduction velocity) was activated during the following minute. Although this was the $\mathrm{CMH}$ unit in our sample with the most prominent histamine response observed, the activation is apparently too weak to match the itch sensations induced by histamine iontophoresis (see Fig. 1). All other CMH units that responded at all after histamine iontophoresis showed even weaker responses, usually confined to the first 3 min after current termination.

Figure 3 summarizes the histamine responses of all units in our sample. Because they were characterized with the marking method, the measure of responsiveness was "number of activation periods," i.e., number of transient increases in latency that occurred in the $15 \mathrm{~min}$ after histamine delivery. There is a distinct population of units showing sustained activation by histamine, and this population consists only of mechanically insensitive $\mathrm{CH}$ and $\mathrm{CM}_{\mathrm{i}} \mathrm{H}_{\mathrm{i}}$ units. This population is unlikely to be a chance selection of afferent $\mathrm{C}$-fibers, because $\mathrm{CH}$ and $\mathrm{CM}_{\mathrm{i}} \mathrm{H}_{\mathrm{i}}$ units constitute only about $20 \%$ in an unselected population of afferent C-fibers (Torebjörk et al., 1996).

One additional finding supports the notion that the eight histamine-sensitive $\mathrm{CH}$ and $\mathrm{CM}_{\mathrm{i}} \mathrm{H}_{\mathrm{i}}$ units in our sample represent a particular class of $\mathrm{C}$-fibers, namely their exceptional slow conduction velocities (Fig. 4). Mean cvs of CMHs in the present sample were $\sim 0.9 \mathrm{~m} / \mathrm{sec}$, in agreement with previous studies 


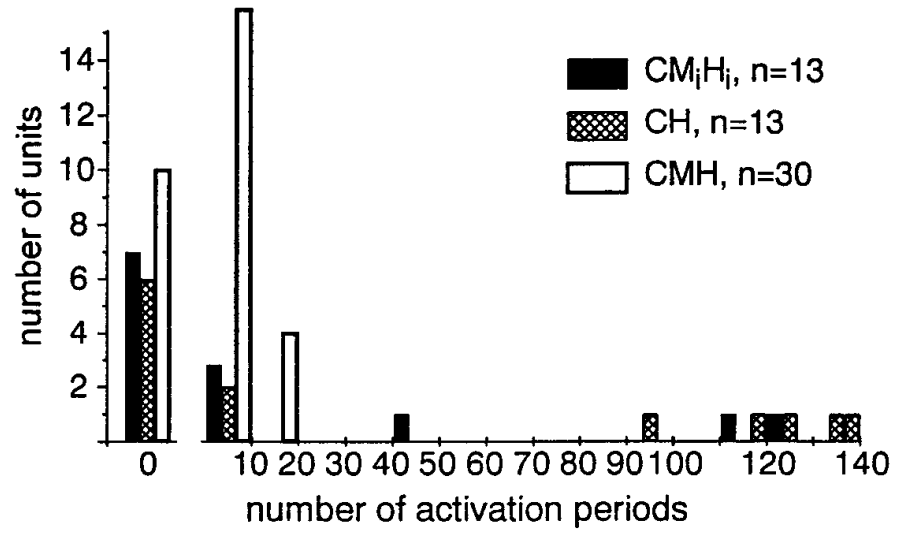

Figure 3. Summary of histamine responses in different classes of Cfibers. Activity after histamine iontophoresis is represented as number of activation periods, i.e., stimulus cycles in which marking occurred. The three columns to the left represent units that did not respond at all to histamine. The eight units with more than 40 activation periods showed sustained responses.

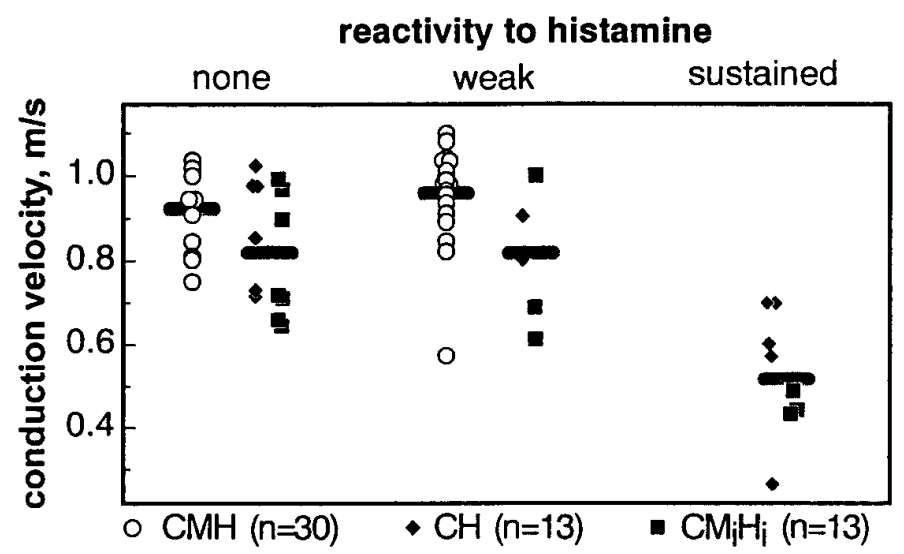

Figure 4. Conduction velocities, depicted on the ordinate, of C-fibers differentiated in classes according to their responsiveness to mechanical and heat stimulation $\left(\mathrm{CMH}, \mathrm{CH}\right.$, and $\left.\mathrm{CM}_{\mathrm{i}} \mathrm{H}_{\mathrm{i}}\right)$ and according to their insensitivity, weak sensitivity, and sustained responses to histamine. Units with sustained responses to histamine have significantly lower conduction velocities.

(Schmidt et al., 1995), regardless of whether the units were unresponsive or weakly responsive to histamine. $\mathrm{CH}$ and $\mathrm{CM}_{\mathrm{i}} \mathrm{H}_{\mathrm{i}}$ units with sustained histamine responses had mean cvs of 0.52 $(\mathrm{SD}, 0.15) \mathrm{m} / \mathrm{sec}$. These units with sustained histamine responses had significantly slower cvs compared with CMHs (Mann-Whitney $U$ test, $p<0.0001$ ) and also to mechanically insensitive $\mathrm{CH}$ and $\mathrm{CM}_{\mathrm{i}} \mathrm{H}_{\mathrm{i}}$ units with or without weak histamine sensitivity (Mann-Whitney $U$ test, $p=0.02$ and 0.001 , respectively). Within the population of units without and with weak sensitivity to histamine, the cvs of mechanically insensitive $\left(\mathrm{CH}\right.$ and $\left.\mathrm{CM}_{\mathrm{i}} \mathrm{H}_{\mathrm{i}}\right)$ units were significantly lower than those of CMHs (Mann-Whitney $U$ test, $p=0.01$ ).

The slow cvs of the histamine sensitive units indicate rather small axon diameters, and this may explain why we were not able to determine the innervation territories of these units by transcutaneous electrical stimulation as in previous studies on mechanically responsive and mechanically insensitive C-units (Schmelz et al., 1994). Probably the activation thresholds of the terminal branches were so high or the terminals were deep in the skin, so

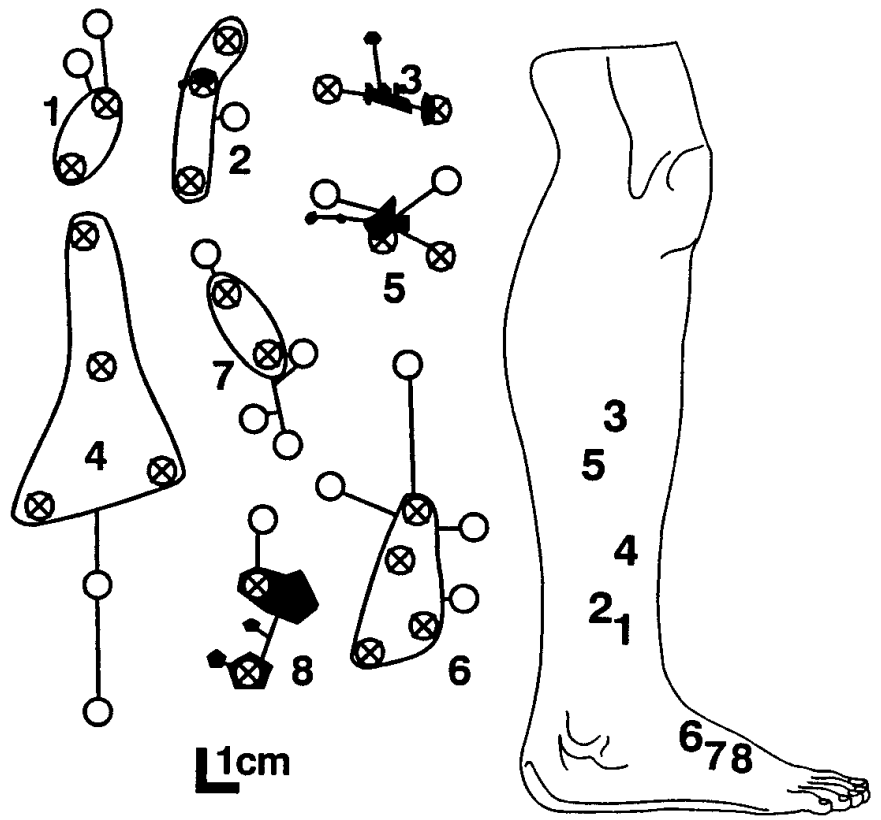

Figure 5. Transcutaneous excitation and distribution of histaminesensitive spots of histamine-sensitive C-fibers labeled 1-8. Black areas represent spots from which the respective unit was excited by transcutaneous stimulation. Circles with crosses, Histamine iontophoresis leading to excitation. Open circles, Unresponded histamine iontophoresis. Locations of the innervation territories are shown on the schematic leg on the right.

that transcutaneous activation would have required stimulus currents that would have been intolerable to the subjects. Instead, we tried to determine the innervation territories of these units by iontophoresis of histamine to various spots in the vicinity of the intracutaneous needles from which the units were electrically excited. The diameter of the probe for delivery of histamine was $6 \mathrm{~mm}$ (see Materials and Methods), and these tests could be performed only at intervals of a minimum of $15 \mathrm{~min}$, restricting, of course, the resolution of this assessment of innervation territories. However, lateral spread of the histamine can probably be excluded, because the histamine-induced weal was always confined to the area under the iontophoresis probe. Despite the limited spatial resolution of the method for assessment of innervation territories, the results shown in Figure 5 are remarkable. One of the units had an innervation territory with a longest extension of at least $85 \mathrm{~mm}$; another one had a territory of at least $45 \mathrm{~mm}$ diameter. In comparison, in a large sample of CMH units the median diameter of the longest axis of the innervation territories was $24.4 \mathrm{~mm}$ on the lower leg and $15 \mathrm{~mm}$ on the foot dorsum, which is smaller than average flares induced by histamine iontophoresis (Schmidt et al., 1997). This indicates that at least some of the histamine-sensitive units have exceptionally large innervation territories despite their tiny axons.

\section{DISCUSSION}

Because previous studies have failed to identify any particular class of primary sensory neurons that would respond preferentially to pruritogenic stimuli, itch has been hypothesized to be induced by low-frequency excitation of nociceptors also mediating pain sensation (von Frey, 1922), by a particular pattern of activation (Wall and Cronly-Dillon, 1960), or by activation of a subpopulation of polymodal C-fibers (Tuckett and Wei, 1987; Handwerker, 1992). There is no substantial evidence for any of 
these hypotheses. On the contrary, results from transcutaneous (Tuckett, 1982) and intraneural electrical stimulation (Torebjörk and Ochoa, 1981) in humans have proven that the frequency or pattern of stimulation of nociceptive fibers does not influence the quality of itch versus pain. Furthermore, the size and intensity of the neurogenic flare induced by itch-provoking histamine are larger and more persistent than the flare induced by painprovoking mechanical stimuli, which, in turn, excite $\mathrm{CMH}$ units more effectively than histamine. This seems to rule out CMHs as mediators of histamine flare and concomitant itch.

Instead, the evidence put forward in the present report favors the concept that there are histamine-sensitive receptors with unique properties that make them appropriate for signaling itch. That those receptors are supplied by $\mathrm{C}$-fibers is to be expected, because itch sensibility is not lost by peripheral nerve compression block until C-fiber conduction is impaired (Handwerker et al., 1987). Their unusually wide innervation territories in the skin fit with the exceptionally large flares observed after histamine application (Handwerker et al., 1987; Magerl et al., 1990).

A sensor for itch should react preferentially to pruritogenic stimuli, although it does not need to be entirely specific in this respect. The units described in this paper were in part $\mathrm{CH}$; i.e., they were also excited by heating the skin in the range of $41-46^{\circ} \mathrm{C}$ and also by capsaicin application. This is interesting from a clinical point of view, because it is known that warming often enhances itch (Fruhstorfer et al., 1986). On the other hand, these histamine-sensitive $\mathrm{CH}$ units do not necessarily contribute to the sensation of warmth or burning caused by heat or capsaicin application, which is probably mediated by the large population of $\mathrm{CMH}$ and $\mathrm{CH}$ units with little histamine sensitivity.

There are probably four main reasons why the histaminesensitive units have not been described before: (1) species differences and the lack of animal models for itch; (2) the insensitivity of histamine-sensitive units to mechanical stimuli; (3) the fact that histamine has not been used systematically as a search stimulus in human studies; and (4) the slow conduction of their axons.

(1) Studies on experimental animals related to itch are not easy to interpret, because their scratching behavior may be stereotypical and unspecific for itch. Furthermore, there are no flare responses in rat or cat, and mast cells in rat skin contain little histamine but instead serotonin, which is lacking in human mast cells (Wallengren, 1993).

(2) Until recently it was generally held that all afferent $\mathrm{C}$-fibers in human skin nerves are polymodal, i.e., CMH. Usually, mechanical search stimuli were used, which obviously excluded silent $\mathrm{CM}_{\mathrm{i}} \mathrm{H}_{\mathrm{i}}$ and $\mathrm{CH}$ units from sampling.

The mechanical insensitivity of histamine-sensitive $\mathrm{C}$-fibers seems to be at variance with the well known observation that itch can also be induced by mechanical stimulation. However, von Frey (1922) noted the long latency of itch responses to stimulation of "pain points" in the skin and speculated about a chemical mediator. That is, mechanical excitation of histamine units may be secondary to the mechanically induced release of endogenous mediators including histamine. Furthermore, histamine-sensitive $\mathrm{CM}_{\mathrm{i}} \mathrm{H}_{\mathrm{i}}$ and $\mathrm{CH}$ units are likely to be sensitized to mechanical stimulation as are other $\mathrm{CM}_{\mathrm{i}} \mathrm{H}_{\mathrm{i}}$ and $\mathrm{CH}$ nociceptors (Schmidt et al., 1995).

(3) In early microneurography studies there were anecdotal reports of burst-like discharges in polymodal C-fibers after stimulation of the skin with nettles, which induced mixed sensations of itch and stinging pain (Van Hees and Gybels, 1972; Torebjörk, 1974). Only in one study was histamine applied systematically to
$\mathrm{CMH}$ units, and most of them were unresponsive or responded weakly. One unit showing sustained discharges should probably be reclassified as $\mathrm{CH}$ on the basis of our present knowledge because of its high initial mechanical threshold (Handwerker et al., 1991).

(4) The greatest obstacle in the search for histamine units was obviously their small axon diameter, leading to a sampling bias against them attributable to the high electrical activation thresholds and low extracellular spike signals. Because of this presumed sampling bias, we cannot reasonably speculate on their frequency of occurrence.

It has been proven that afferent $\mathrm{C}$-units are tapering toward the periphery. Because we measured average conduction velocities between nerve terminals and recording site at the knee level, we do not know the conduction velocities, and hence the axon diameters, at the recording site itself. Interestingly, a small group of $\mathrm{CH}$ units with average cvs of $0.5 \mathrm{~m} / \mathrm{sec}$ has been found in one study in the monkey skin. These units were not tested with histamine, however (Baumann et al., 1991).

With the discovery of histamine-sensitive C-fibers among the slowest conducting mechanically insensitive $\mathrm{C}$-fibers, the spectrum of afferent nerve fibers has been expanded, and this was achieved by the application of the computer-assisted marking technique in microneurography. This technique augments the power of microneurography mainly for two reasons: (1) it allows clear identification of units with spikes of low signal-to-noise ratio by their unique conduction velocity; this identification is supported by the long distance between stimulating electrodes at the foot and recording electrodes at the knee level, which excludes superposition of spikes from different units; and (2) the marking technique enables the study of identified single $\mathrm{C}$-units over extended periods, up to several hours, although spike forms often change during the observation period. Without this novel technique, the search for the tiny histamine-sensitive $\mathrm{C}$-units probably would not have led to reliable results. It will be a future task to refine our techniques further to allow routine recordings of these smallest nerve fibers in pathophysiological studies.

\section{REFERENCES}

Baumann TK, Simone DA, Shain CN, LaMotte RH (1991) Neurogenic hyperalgesia: the search for the primary cutaneous afferent fibers that contribute to capsaicin-induced pain and hyperalgesia. J Neurophysiol 66:212-227.

Beck PW, Handwerker HO, Zimmermann M (1974) Nervous outflow from the cat's foot during noxious radiant heat stimulation. Brain Res 67:373-386.

Bessou P, Perl ER (1969) Responses of cutaneous sensory units with unmyelinated fibers to noxious stimuli. J Neurophysiol 32:1025-1043.

Fleischer E, Handwerker HO, Joukhadar S (1983) Unmyelinated nociceptive units in two skin areas of the rat. Brain Res 267:81-92.

Forster C, Handwerker HO (1990) Automatic classification and analysis of microneurographic spike data using a PC/AT. J Neurosci Methods 31:109-118.

Fruhstorfer H, Hermanns M, Latzke L (1986) Effects of thermal stimulation on clinical and experimental itch. Pain 24:259-269.

Gybels J, Handwerker HO, Van Hees J (1979) A comparison between the discharges of human nociceptive nerve fibres and the subject's ratings of his sensations. J Physiol (Lond) 292:193-206.

Hallin RG, Torebjörk HE, Wiesenfeld Z (1982) Nociceptors and warm receptors innervated by $\mathrm{C}$ fibres in human skin. J Neurol Neurosurg Psychiatry 45:313-319.

Handwerker HO (1992) Pain and allodynia, itch and alloknesis: an alternative hypothesis. APS J 1:135-139.

Handwerker HO, Magerl W, Klemm F, Lang E, Westerman RA (1987) Quantitative evaluation of itch sensation. In: Fine afferent nerve fibres and pain (Schmidt RF, Vahle-Hinz C, eds), pp 463-473. Weinheim: VCH. 
Handwerker HO, Forster C, Kirchhoff C (1991) Discharge patterns of human c-fibers induced by itching and burning stimuli. J Neurophysiol 66:307-315.

LaMotte RH (1992) Subpopulations of "nocifensor neurons" contributing to pain and allodynia, itch and alloknesis. APS J 1:115-126.

LaMotte RH, Campbell JN (1978) Comparison of responses of warm and nociceptive C-fiber afferents in monkey with human judgments of thermal pain. J Neurophysiol 41:509-528.

LaMotte RH, Simone DA, Baumann TK, Shain CN, Alreja M (1988) Hypothesis for novel classes of chemoreceptors mediating chemogenic pain and itch. In: Proceedings of the Vth world congress on pain (Dubner R, Gebhart GF, Bond M, eds), pp 529-535. Amsterdam: Elsevier.

Lynn B, Carpenter SE (1982) Primary afferent units from the hairy skin of the rat hind limb. Brain Res 238:29-43.

Magerl W, Westerman RA, Mohner B, Handwerker HO (1990) Properties of transdermal histamine iontophoresis: differential effects of season, gender, and body region. J Invest Dermatol 94:347-352.

Meyer RA, Campbell JN (1981) Evidence for two distinct classes of unmyelinated nociceptive afferents in monkey. Brain Res 224:149-152.

Schmelz M, Schmidt R, Ringkamp M, Handwerker HO, Torebjörk HE (1994) Sensitization of insensitive branches of C nociceptors in human skin. J Physiol (Lond) 480:389-394.

Schmelz M, Forster C, Schmidt R, Ringkamp M, Handwerker HO, Torebjörk HE (1995) Delayed-responses to electrical stimuli reflect c-fiber responsiveness in human microneurography. Exp Brain Res 104:331-336.

Schmidt R, Schmelz M, Forster C, Ringkamp M, Torebjörk HE, Handwerker HO (1995) Novel classes of responsive and unresponsive C nociceptors in human skin. J Neurosci 15:333-341.

Schmidt R, Schmelz M, Ringkamp M, Handwerker HO, Torebjörk HE (1997) Innervation territories of mechano-responsive C-nociceptor units in human skin. J Neurophysiol, in press.

Simone DA, Ngeow JY, Whitehouse J, Becerra Cabal L, Putterman GJ,
LaMotte RH (1987) The magnitude and duration of itch produced by intracutaneous injections of histamine. Somatosens Res 5:81-92.

Simone DA, Nolano G, Wendelschafer-Crabb G, Kennedy WR (1996) Intradermal injection of capsaicin in humans: diminished pain sensation with rapid degeneration of intracutaneous nerve fibers. Soc Neurosci Abstr 22:1802.

Torebjörk HE (1974) Afferent C units responding to mechanical, thermal and chemical stimuli in human non-glabrous skin. Acta Physiol Scand 92:374-390.

Torebjörk HE, Hallin RG (1974) Responses in human A and C fibres to repeated electrical intradermal stimulation. J Neurol Neurosurg Psychiatry 37:653-664.

Torebjörk HE, Ochoa JL (1981) Pain and itch from C fiber stimulation. Soc Neurosci Abstr 7:228.

Torebjörk HE, Schmelz M, Handwerker HO (1996) Functional properties of human cutaneous nociceptors and their role in pain and hyperalgesia. In: Neurobiology of nociceptors (Belmonte C, Cervero F, eds), pp 349-369. Oxford: Oxford UP.

Tuckett RP (1982) Itch evoked by electrical stimulation of the skin. J Invest Dermatol 79:368-373.

Tuckett RP, Wei JY (1987) Response to an itch-producing substance in cat: II. Cutaneous receptor populations with unmyelinated axons. Brain Res 413:95-103.

Van Hees J, Gybels J (1972) Pain related to single afferent C-fibres from human skin. Brain Res 48:397-400.

Van Hees J, Gybels J (1981) C nociceptor activity in human nerve during painful and non painful skin stimulation. J Neurol Neurosurg Psychiatry 44:600-607.

von Frey M (1922) Zur Physiologie der Juckempfindung. Arch Neerland Physiol 7:142-145.

Wall PD, Cronly-Dillon JR (1960) Pain, itch and vibration. Arch Neurol 2:365-375.

Wallengren J (1993) The pathophysiology of itch. Eur J Dermatol 3: 643-647. 